\title{
A technical note on application of internally finned tubes in solar parabolic trough absorber pipes
}

\author{
Javier Muñoz, Alberto Abánades* \\ Universidad Politécnica de Madrid, J. Gutiérrez Abascal, 2-28006 Madrid, Spain
}

Received 25 March 2010; received in revised form 28 December 2010; accepted 10 January 2011

\begin{abstract}
The heterogeneous incoming heat flux in solar parabolic trough absorber tubes generates huge temperature difference in each pipe section. Helical internal fins can reduce this effect, homogenising the temperature profile and reducing thermal stress with the drawback of increasing pressure drop. Another effect is the decreasing of the outer surface temperature and thermal losses, improving the thermal efficiency of the collector. The application of internal finned tubes for the design of parabolic trough collectors is analysed with computational fluid dynamics tools. Our numerical approach has been qualified with the computational estimation of reported experimental data regarding phenomena involved in finned tube applications and solar irradiation of parabolic trough collector. The application of finned tubes to the design of parabolic trough collectors must take into account issues as the pressure losses, thermal losses and thermo-mechanical stress, and thermal fatigue. Our analysis shows an improvement potential in parabolic trough solar plants efficiency by the application of internal finned tubes.
\end{abstract}

\section{Introduction}

The efficiency in the process to produce electricity by solar thermal technologies can be roughly expressed, neglecting parasitic losses for the sake of simplicity, by the product of the solar field and cycle efficiencies. $\eta_{\text {field }}$ stands for the field efficiency, what constitutes the ratio between the heat transferred to the heat transfer fluid and the beam solar radiation times aperture area of the solar field, and $\eta_{\text {cycle }}$ is the efficiency in the transformation of that heat into electricity through the thermodynamic cycle and the electric generator.

The field efficiency depends, for a given solar field configuration fixing parameters as mirror reflectivity, alignment, tracking ability and coating properties, mainly on the radiation thermal losses due to the temperature that the absorbing coating will reach. The absorber coating achievable temperature is technologically limited up to now (Farooq and Raja, 2008) by the maximum thermal stress that can be assumed in the steel pipes and the radiation absorbing layer (Eck et al., 2003). Obviously, a higher coating temperature will increase radiation thermal losses, reducing the field efficiency, but potentially increasing the outlet heat transfer fluid exergy. The cycle efficiency depends roughly on the exergy that can be transferred to the thermodynamic cycle, and, therefore, increases with the outlet temperature of the solar field heat transfer fluid. A loss of exergy is produced by the temperature difference between the absorber surface and the transfer fluid. The reduction of the thermal resistance between the inner tube side and the heated fluid imply a reduction of the exergy losses that are inferred by heat convection into the absorber tube and an increase in the outlet heat transfer fluid 
temperature that should remain always under the limits of the heat transfer fluid thermal stability. It is clear that an enhancement of the convection heat transfer into the tube of parabolic trough collectors, for a limited temperature coating, will increase the overall efficiency of this kind of solar plants, as the exergy gain in the heat transfer fluid increases.

Another relevant issue that must be addressed concerning trough absorbing tube design and operation is the minimization of the annular vacuum losses with time due to air permeation through closures, what limits the lifetime of these devices. Such air filtration has as one of its main weak points in the glass-metal seal that must keep the vacuum between the glass envelope and the absorbing surface in spite of the differential thermal elongation between both materials. Such elongation induced by the temperature difference between the glass and the absorbing tube, determined by radiation exchange between both surfaces, and their expansion coefficient. Such sealing structure depends on the thermal expansion coefficient, material conductivity and Young's modulus (a material property related to its stiffness, defined as the ration between the stress and the material strain in the elastic range), and the sealing structure (Lei et al., 2010), producing a bending moment and shearing forces that depend on temperature gradients in the absorbing tube in normal operation and under transients.

The heating profile in the absorber tube resulting from the concentrating parabolic mirror optics has been analysed and measured (Unidad de Formación en Energía y Medioambiente, 2006; Pfänder et al., 2007) having a shape as shown in Fig. 1, whose integration along the tube should provide the heat flux irradiating the absorbing tube. The effect of the solar heating is vanishing with high conductivity tubes (Eck et al., 2003), but its effects must be analysed when a low mass flow transient takes place, with the risk of contact between the glass envelope and the absorbing tube as a result of the tube bending, producing a hot point in the glass cover and its breakage.

The homogenisation of the temperature field in the absorbing tubes is one of the relevant solutions that can be proposed to avoid breaking risks and air filtration in the absorber tube. A mean to reduce temperature gradients in the metallic tube is the enhancement of the convection heat transfer mechanisms that carry the absorbed thermal energy to the heat transfer fluid. In this paper, the addition of internal fins in the collector absorbing pipes is analysed in order to assess the technological viability of such design chance in state-of-the art absorbing tubes. In particular, we will pay attention to its thermal-hydraulic behaviour, what affects the thermal efficiency of the collector and the parasitic losses that are induced by pumping power due to the expected increase in pressure losses for the application of internal finned tubes as substrate for the absorbing coating.

The plant efficiency, including the parasitic losses, can be expressed with the following relation:

$\eta_{t-e}=\eta_{\text {field }} \cdot \eta_{\text {cycle }}-\frac{W_{B}}{A_{F} \cdot \mathrm{DNI}}$

where the efficiency penalty due to the parasitic losses are formulated in function of the pumping electric consumption $\left(W_{B}\right)$ and the direct normal irradiance (DNI) times the field surface area $\left(A_{F}\right)$. The utilisation of internal finned tubes will produce an increase on the required heat transfer fluid pumping that must be taken into account for a complete cost-benefit analysis of this design proposal.

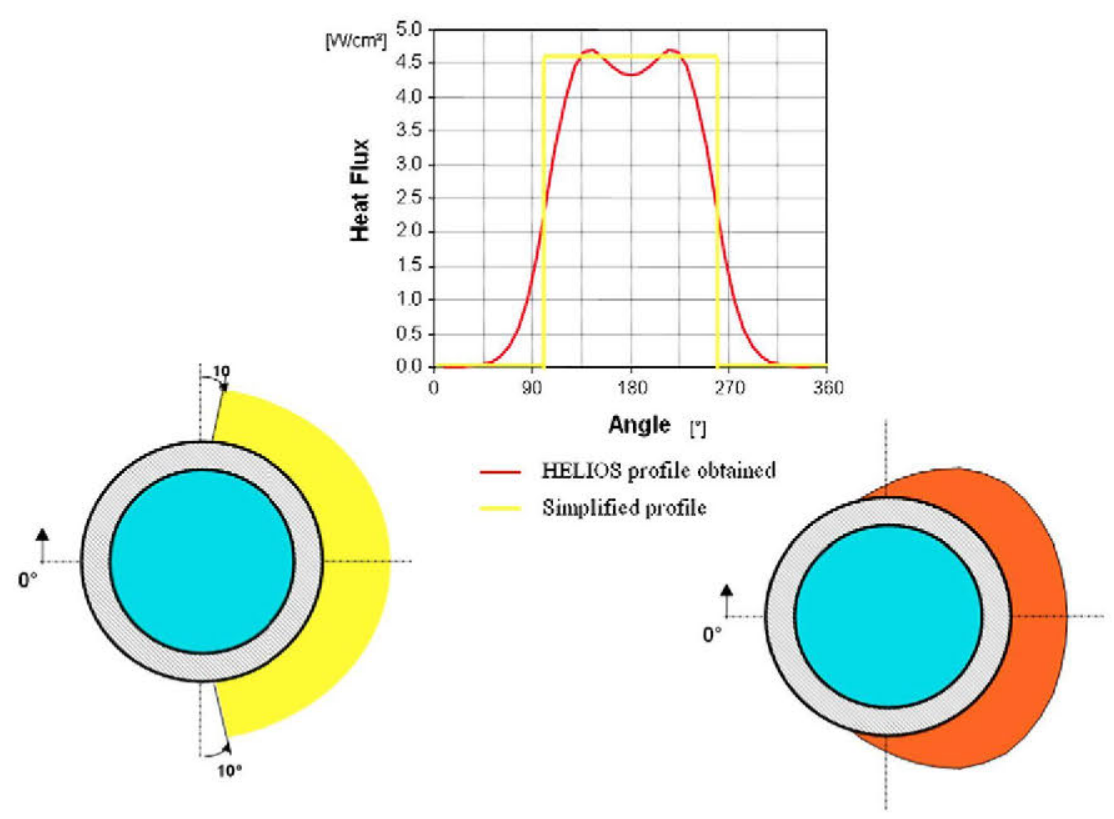

Fig. 1. Usual thermal power flux for an ET-II collector obtained with the HELIOS code and the simplified profile proposed for its simulation at nominal conditions $\left(\mathrm{DNI}=900 \mathrm{~W} / \mathrm{m}^{2}\right)$ (Unidad de Formación en Energía y Medioambiente, 2006). 
Table 1

Tube configurations for finned parabolic trough collectors.

\begin{tabular}{|c|c|c|c|c|c|c|}
\hline \multirow[t]{2}{*}{ Tube } & \multirow{2}{*}{$\begin{array}{l}\text { External structure } \\
\text { Outer diameter }(\mathrm{mm})\end{array}$} & \multirow{2}{*}{$\begin{array}{l}\text { Tube } \\
\text { Thickness (mm) }\end{array}$} & \multicolumn{4}{|l|}{ Internal surface } \\
\hline & & & Fin height (mm) & Number of starts & Helix angle (degrees) & Internal nominal diameter $(\mathrm{mm})$ \\
\hline$\# 1$ & 70 & 2 & 2 & 10 & 25 & 66 \\
\hline$\# 2$ & 70 & 2 & 2 & 5 & 25 & 66 \\
\hline \#3 & 70 & 2 & 2 & 10 & 16 & 66 \\
\hline$\# 4$ & 70 & 2 & 2 & 5 & 16 & 66 \\
\hline
\end{tabular}

\section{Methodology: simulation}

The analysis of this design proposal has been done by numerical estimation of the absorbing tube performance from the thermal-hydraulic point of view, evaluating its thermal behaviour and the pressure losses. A commercial multipurpose computational fluid dynamics (CFD) code FLUENT 6.3 (ANSYS Inc., 2008) has been used as main tool in our analysis. Such code is used in many industries and fields for local thermal hydraulic analysis, including concentrated solar collectors (Ravi Kumar and Reddy, 2009), providing estimation of thermal systems that can be used for design improvements acting as a virtual laboratory or test-bench.

The main reason to use a CFD tool is to study the temperature profile. There are studies as the one of Forristal (2003) with EES code (F-Chart Software, 2005) validated with experiments carried out by Sandia Laboratories (Dudley et al., 1994). In that experimental work a real thermal profile was not required, only the thermal balance and the determination of the mean temperatures. In our case is essential to estimate the temperature profile because the goal of homogenisation of thermal profile goes through the contour condition of a heterogeneous, actual heat flux.

Every computational tool must be qualified for its purpose of application as a compulsory step to have confidence on its results and estimations. For such reason, we have qualified our numerical model with existing experimental data extracted from the available literature for hydraulic and thermal phenomena. From the hydraulic point of view, the validation was made with the results from the experiments carried out with internally helical tubes by Zdaniuk et al. (2008). For the thermal point of view, the qualification of the CFD model was made with the AZTRAK experiments results (Moss and Brosseau, 2007). Both qualification resulted in very good agreements between the available data and the estimation of our model.

\section{Results and comparison}

Four fin configurations have been studied (Table 1) with $70 \mathrm{~mm}$ outer diameter tubes, as it is the case of most available tubes for commercial parabolic trough solar plants as PTR70 in EUROTROUGH collectors or the heat collecting elements of SOLEL LS3 collectors. The total length for all simulated tubes is $7795 \mathrm{~m}$, as it was the case of the AZTRAK facility for a better comparison with the plain

tube model. Fig. 2 shows the definition of the characteristics of a helical finned tube as the helix angle and fin height. Fig. 3 shows our model for tube \#1, with ten starts, meaning ten fins at each cross section.

A brief summary of the evaluation of the performance of a plain internal tube applied to solar thermal parabolic trough collector for electricity production, as the case of the LS2 (AZTRAK), compared with a proposed set of internal finned tubes cooled by Syltherm 800 as heat transfer fluid is shown in Table 2. $\Delta T_{\text {surface }}$ is the difference between the maximum external and internal surface, and $\Delta T_{\text {tube }}$ is the difference between the maximum external
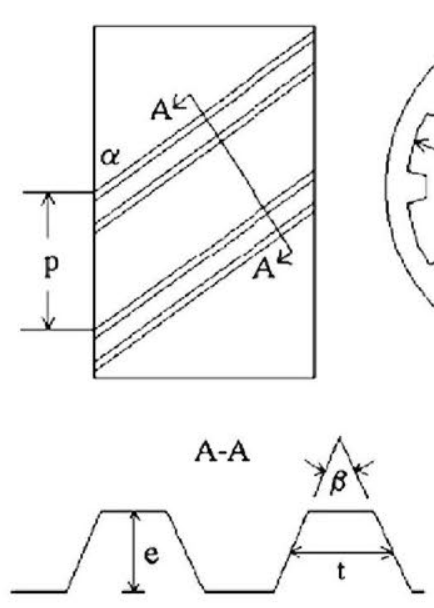

Fig. 2. Geometric variables of the helical fin (ANSYS Inc., 2008).

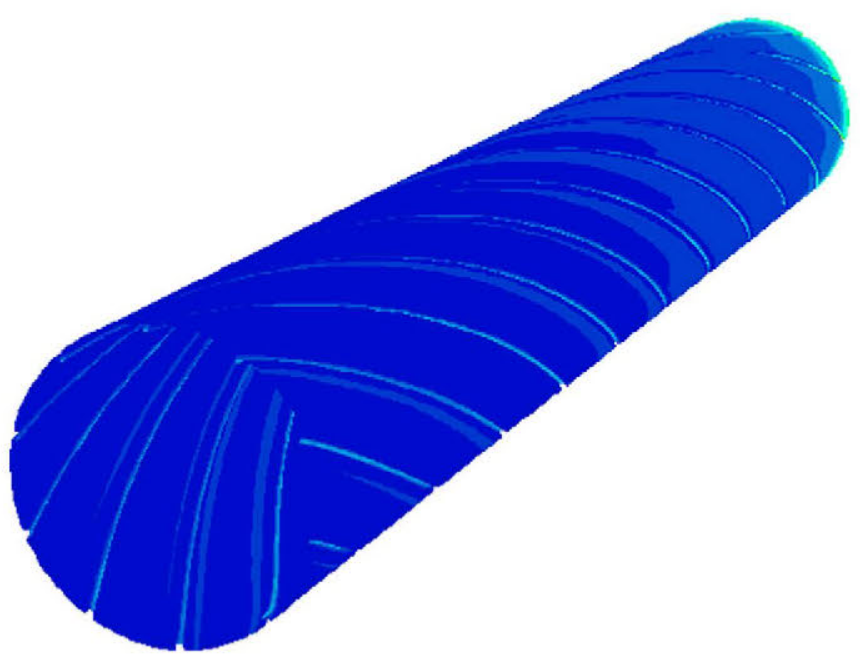

Fig. 3. Model for each partition of tube \#1 corresponding to the length of a helix turn. 
Table 2

Summary of the performance of plain and finned simulated tubes for parabolic trough collectors.

\begin{tabular}{|c|c|c|c|c|c|}
\hline & LS2 & Tube \#1 & Tube \#2 & Tube \#3 & Tube \#4 \\
\hline Pressure losses (Pa) & 114.0 & 164.9 & 144.1 & 141.0 & 128.4 \\
\hline Diff. with LS2 (\%) & & 44.7 & 26.4 & 23.7 & 12.6 \\
\hline$\Delta T_{\text {surfaces }}\left({ }^{\circ} \mathrm{C}\right)$ & 176.5 & 103.1 & 129.2 & 121.4 & 148.3 \\
\hline Diff. with LS2 (\%) & & 41.6 & -26.8 & -31.2 & -16.0 \\
\hline Thermal losses $\left(\mathrm{W} / \mathrm{m}^{2}\right)$ & 2109.2 & 1717.3 & 1858.3 & 1809.9 & 1962.6 \\
\hline Diff. with LS2 (\%) & & -18.6 & -11.9 & -14.2 & -7.0 \\
\hline$\Delta T_{\text {tube }}\left({ }^{\circ} \mathrm{C}\right)$ & 176 & 104 & 129 & 122 & 149 \\
\hline Diff. with LS2 (\%) & & -40.9 & -26.7 & -30.7 & -15.3 \\
\hline
\end{tabular}

surface temperature and the heat transfer fluid, what included the fluid boundary layer.

The red coloured cells highlight the quantification of the drawback effect of the application of internal finned tube due to the increase of the pressure losses in the tube. The improvements in the performance of the tube are remarked in blue with the relative improvement of the temperature differences and thermal losses. Every relative figure has as reference the $\mathrm{LS} 2$ value.

The reduction of the thermal losses and temperature differences either is favoured by the increase in the number of fins and, therefore, the heat transfer area. Tubes \#1 and \#3, with more fins, produce a better performance from the thermal point of view, with a losses reduction between 18.6 and $14.2 \%$. The higher helix angle in the case of tube \#1 implies a higher heat transfer area, and a better thermal performance. Nevertheless, the higher helix angle implies an increase in turbulence and higher pressure losses. Therefore tube \#3, with a lower helix angle, increases the pressure losses only a $23.7 \%$. The compromise between thermal losses and parasitic power suggest a tube design close to tube \#3 with a moderate helix angle.

\section{Conclusion}

This paper has analysed the effect of the utilisation of internal finned tubes for the design of parabolic trough collectors with computational fluid dynamics tools. Our numerical approach has been qualified with the estimation of experimental data. The application of finned tubes to the design of parabolic trough collectors must take into account changes in the pressure losses, thermal losses and thermomechanical stress and thermal fatigue. We have proposed a set of finned tube configurations that has been compared with a reference commercial tube. Our analysis shows how the parasitic losses associated to the pressure losses in the tube will increase with the number of fins and its helix angle. On the other hand, thermal losses and temperature gradients are reduced producing an increase in the thermal and exergetic efficiency of the collector. In previous work, for a 20 MWe solar plant cooled by oil (Montes et al., 2008), the parasitic losses were evaluated in $2.6 \%$ (536 kWe). With this value and according to our analysis are obtained a $40 \%$ increase of parasitic losses (hence $750 \mathrm{kWe}$ ) with a $3 \%$ improvement of the collector efficiency (thus producing 20.6 MWe). This result will lead to a plant performance enhancement of $2 \%$, with an expected reduction of operation and maintenance cost due to the reduction of the tube replacement rate. Reduction motivated by the decrease in tubes mechanical fatigue that would compensate the cost increase of the finned collector tube that should be determined in detail. We are optimistic about the collector cost increase as the steel addition is less than $2 \%$ and its cost is much lower than the absorbing coating, the glass and the glass-tube vacuum system. Nevertheless, the effect of the plant size and power should be evaluated in detail, but we believe that an optimisation of such design integrated into a thermal concentrated solar plant can be an open research activity for the future.

\section{References}

ANSYS Inc., 2008. CFD Flow Modeling Software \& Solutions from FLUENT, <http://www.fluent.com/>.

Unidad de Formación en Energía y Medioambiente, 2006. Curso sobre sistemas solares de concentración, CIEMAT, 2-11 de octubre de 2006 , Madrid, España.

Dudley, V.E., Kolb, G.J., Mahoney, A.R., et al., 1994. Test Results: SEGS LS-2 Solar Collector, SAND94-1884, Albuquerque, NM: SANDIA National Laboratories, December.

Eck, M., Zarza, E., Eickhoff, M., Rheinländer, J., Valenzuela, L., 2003. Applied research concerning the direct steam generation in parabolic troughs. Solar Energy 74 (4), 341-351.

Farooq, M., Raja, I.A., 2008. Optimisation of metal sputtered and electroplated substrates for solar selective coatings. Renewable Energy 33 (6), 1275-1285.

F-Chart Software, 2005. EES (Engineering Equation Solver), <http:// www.fchart.com>

Forristal, R., 2003. Heat Transfer Analysis and Modeling of a Parabolic Trough Solar Receiver Implemented in Engineering Equation Solver, NREL Technical Report, Golden, Colorado, USA.

Lei, D., Wang, Z., Li, J., 2010. The calculation and analysis of glass-tometal sealing stress in solar absorber tube. Renewable Energy 35 (2), $405-411$.

Montes, M.J., Abánades, A., Martínez-Val, J.M., 2008. Thermodynamic model analysis of parabolic trough collectors using oil, water/steam or molten salt as heat transfer fluid. In: 14th Biennial CSP SolarPaces Symposium, 4-7 March, Las Vegas, Nevada, USA.

Moss, T., Brosseau, D., 2007. Testing capabilities NSTTF (AZTRAK) rotating platform, Sandia National Laboratories, Albuquerque, New Mexico, USA.

Pfänder, M., Lüpfert, E., Pistor, P., 2007. Infrared temperature measurements on solar trough absorber tubes. Solar Energy 81, 629-635.

Ravi Kumar, K., Reddy, K.S., 2009. Thermal analysis of solar parabolic trough with porous disc receiver. Applied Energy 86 (9), 1804-1812.

Zdaniuk, G.J., Chamra, L.M., Mago, P.J., 2008. Experimental determination of heat transfer and friction in helically-finned tubes. Experimental Thermal and Fluid Science 32 (3), 761-775. 